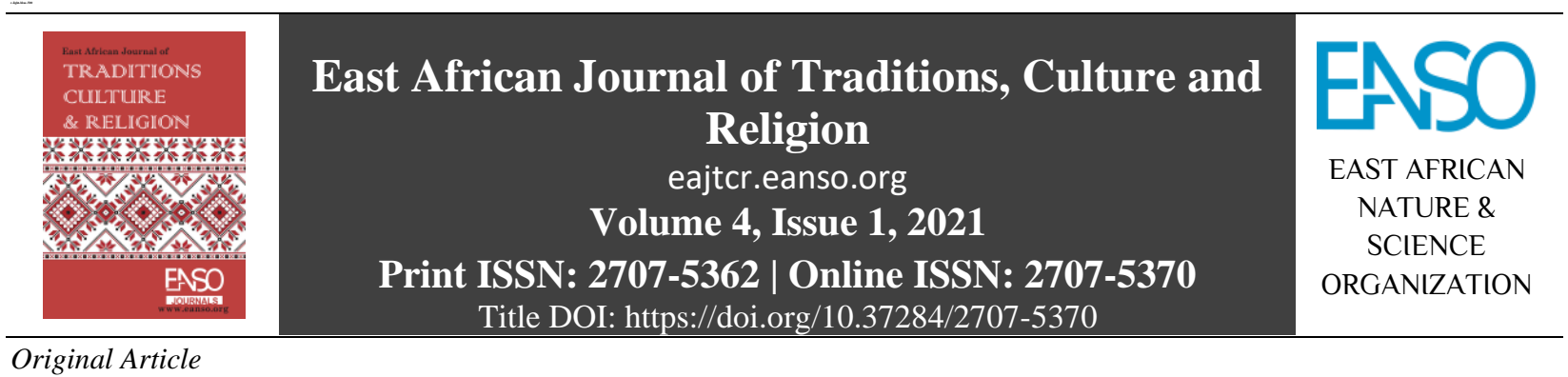

\title{
The Role of the Church in the Transformation of 'No Sex Before Marriage' Social Norm in Tanzania: From Shameful to Responsible Sex.
}

\author{
Adalbertus Kamanzi ${ }^{1 *} \&$ Anna Shilunga ${ }^{1}$ \\ ${ }^{1}$ Senior Lecturer University of Namibia, Private Bag 13301, Windhoek Namibia. \\ *Author for Correspondence Email: akamanzi@unam.na
}

Article DOI: https://doi.org/10.37284/eajtcr.4.1.563

\section{Date Published: ABSTRACT}

08 November 2021 Social norms comprise of "the rules and standards that are understood by members of a group, and that guide and/or constrain social

Keywords: behaviour without the force of laws. Social norms are the public rules of action and thought, acting as the backbone of societal habits,

Church, routines, and customs, and legal frames. In African settings, influence No Sex Before Marriage, is organized mostly along with the gender, age, and religious Social Norm, Thual activities of the adolescents. The standing norm drawn from the structures. Religious people play the spiritual and advisory roles in the religious and social beliefs is "no sex before marriage." In the Shameful to Responsible Sex. communities where the research was done, sex was traditionally linked to marriage. Today more than ever, the Church is currently confronted with a divergence of opinion about sexual relationships and marriage. The reality of our society is the question as to whether the traditional understanding of marriage is still relevant as far as facilitating the believers to make meaningful and responsible choices. The intention of this paper is not to dismiss or under-value the institution of marriage, but rather to re-negotiate the structure of sexual matters in our modern society. The paper works with the concept of social norms in order to shed more light on the role of the Church in the transformation of social norms. Using a thematic analysis on a hypothetical case of a pregnancy of an adolescent in a community, data was interrogated with a series of questions for measuring norms, namely: who the reference group is, what is typical in the group, what is approved of in the group, and whether or not the social norm is conjoint or disjoint.

\section{APA CITATION}

Kamanzi, A., \& Shilunga, A. (2021). The Role of the Church in the Transformation of 'No Sex Before Marriage' Social Norm in Tanzania: From Shameful to Responsible Sex. East African Journal of Traditions, Culture and Religion, 4(1), 61-68. https://doi.org/10.37284/eajtcr.4.1.563

61 This work is licensed under a Creative Commons Attribution 4.0 International License. 


\section{CHICAGO CITATION}

Kamanzi, Adalbertus \& Anna Shilunga. 2021. "The Role of the Church in the Transformation of 'No Sex Before Marriage' Social Norm in Tanzania: From Shameful to Responsible Sex”. East African Journal of Traditions, Culture and Religion 4 (1), 61-68. https://doi.org/10.37284/eajtcr.4.1.563.

\section{HARVARD CITATION}

Kamanzi, A., \& Shilunga, A. (2021) "The Role of the Church in the Transformation of 'No Sex Before Marriage' Social Norm in Tanzania: From Shameful to Responsible Sex”, East African Journal of Traditions, Culture and Religion, 4(1), pp. 61-68. doi: 10.37284/eajtcr.4.1.563.

\section{IEEE CITATION}

A. Kamanzi, \& A. Shilunga. "The Role of the Church in the Transformation of 'No Sex Before Marriage' Social Norm in Tanzania: From Shameful to Responsible Sex”, EAJTCR, vol. 4, no. 1, pp. 61-68, Nov. 2021.

\section{MLA CITATION}

Kamanzi, Adalbertus \& Anna Shilunga. "The Role of the Church in the Transformation of 'No Sex Before Marriage' Social Norm in Tanzania: From Shameful to Responsible Sex". East African Journal of Traditions, Culture and Religion, Vol. 4, no. 1, Nov. 2021, pp. 61-68, doi:10.37284/eajtcr.4.1.563.

\section{INTRODUCTION}

It is a shame for the whole family that she got pregnant before marriage; parents expect that one finishes school; there are traditional procedures for marriage; one goes to Church, and she weds, and later she can give birth. This honors the family. So, pregnancy before marriage is shameful ${ }^{1}$

The opening quote above with the view that young girls who get pregnant shame their families, particularly the parents, comes from a female adolescent respondent, herself not married; she is among the respondents on which this paper draws. The understanding of how female adolescents see the constructed world around them indicates much of how the adolescents' sex path is broadly conceived: that they need not have sex before marriage. Thinking and believing that this should necessarily work is an under-estimation of the power of personal beliefs. The adolescents are filled with many more other beliefs regarding sex.

Also implicit in this adolescent's observation is the recognition of the sex social controllers, the parents who are vested with influence from the traditional cultures, on the one hand, and the Church, which is vested with influence from the Christian traditions, on the other. The understanding of how the parents and the Church control sex and recommend it within marriage tells how the institution of marriage is broadly conceived: that without the permission or blessings of the parents and/or of the Church, there is virtually no marriage. Enforcing such belief is an under-estimation of the societal actors' capacity to negotiate and make rules flexible.

We have quite a number of single adults in the church, who are actively sexual and because they have not had partners, they cannot get married; there are men and women with children, but not married; polygamous families are not recognized and people living in such relationships are considered 'out of the norm', and hence sanctioned; there exist high rates of teenage pregnancy, pre-marital multipartnered sex, and the early age of sexual debut for girls. In principle, the Church is supposed to play a nurturing and reconciliatory role to mitigate such challenges; instead, it judges and excludes people by, for example, denying them ordination or denying Sacraments to their parents. The Church is currently confronted with a divergence of opinion about sexual relationships and marriage. The reality of our society is the question as to whether the traditional understanding of marriage is still relevant as far as facilitating the believers to make meaningful and responsible choices.

The intention of this paper is not to dismiss or under-value the institution of marriage, but rather to re-negotiate the structure of sexual matters in our modern society. The paper works with the concept of social norms in order to shed more light on the role of the Church in the transformation of social norms. Using a thematic analysis on a hypothetical

\footnotetext{
${ }^{1}$ Woman, Respondent 7, Village 3.
}

62 This work is licensed under a Creative Commons Attribution 4.0 International License. 
case of a pregnancy of an adolescent in a community, data was interrogated with a series of questions for measuring norms, namely: who the reference group is, what is typical in the group, what is approved of in the group, and whether or not the social norm is conjoint or disjoint ${ }^{2}$. The data was collected through the anchoring vignette method in the north-western part of Tanzania. The data collection aimed at understanding the social norms underlying the adolescent sexuality. This is with the background of having an increase in early pregnancies, impacting on school performance and accessibility. ${ }^{3}$ Vignettes are ordinarily short and constructed in a culturally specific context. ${ }^{4}$ In this research, the constructed vignette was used in all the FGDs in order to allow the discussion prompted by opinions on how to handle the pregnancy of an adolescent. The vignette from which the data for this paper is derived is based on a hypothetical Koku; a 15-year-old girl who got pregnant. The vignette, from which the discussants were adolescents, read as follows:

Koku has a boyfriend from her school who is 18. Lately, she has been sick a lot and throwing up. Eventually, she realizes that she is pregnant. Koku is afraid and scared and decides to run away from home. She tells her friend of her plan, who, in turn, tells Koku's younger sister. Her younger sister informs their parents.

Koku's parents insist that their daughter is not responsible for the pregnancy. They say that Koku is too young and "innocent" to be having sex and accuse her boyfriend of tricking their daughter to have sex with him.
With such vignette, the respondents were able to anchor themselves in the community in order to begin reflecting on the issue of pregnancy of young girls who are not married. The question that began in order to generate discussion was what Koku would do after discovering that she is pregnant.

As a way of analysis, the data were thematically interpreted by responding to the following questions:

- How was early pregnancy dealt with traditionally?

- What are the Church-related consequences of breaking the social norm of no sex before marriage?

- What are the reasons as to why the adolescents have sex?

- How do the adolescents deal with the conflicting personal and social beliefs?

The paper proceeds with the clarification of its analytical concept of social norms, followed by a narrative on the findings regarding the Church and the no sex before marriage norm in terms of how early pregnancy was dealt with traditionally, Church-related of breaking the norm, reasons for having sex, and coping with the conflicting beliefs about sex. The paper winds up with a section that presents the role of the Church in promoting a healthy local normative climate change for sex for the adolescent.

\footnotetext{
${ }^{2}$ Gerry Mackie , Francesca Moneti, Holly Shakya, and Elaine Denny, What Are Social Norms? How Are They Measured? (San Diego, New York: Center on Global Justice, UNICEF, 2015), $9 \& 43$.

${ }^{3}$ It is estimated that 23 percent of girls between 15 to 19 years old begin childbearing; and 39 percent of adolescent girls are either already mothers or pregnant by 18 years old. Accordingly, pregnant female students are coerced to drop out of school, a controversial topic in Tanzania between people who support young mothers to return to school and those who stigmatize the group, because this is a violation to right to education and the consequences being limit to the career opportunities. (See Ivy Sik, Early Motherhood in Tanzania: Exploring the Education, Health and Employment Challenges

of Dar es Salaam's Adolescent Mothers (Scarborough: University of Toronto, 2015),7.

${ }^{4}$ The anchoring vignette methodology is used to correct the so-called 'differential item functioning,' which is a "frame of reference" effect, which can lead to people in similar circumstances to give different responses to questions when there is no "real" difference, at least not from the researcher's perspective. The DIF includes the variation in personal scales on which respondents base subjective answers; it can also include the variation in which respondents understand the same questions (and therefore variations in how they respond). For more insights about the DIF, see Ravallion \& Lokshin (2005); see King \& Wand (2007) for anchoring vignette methodology in general; you can also see Kamanzi (2012) for the use of vignettes in a qualitative study.
}

63 This work is licensed under a Creative Commons Attribution 4.0 International License. 


\section{UNDERSTANDING SOCIAL NORMS}

Social norms comprise of "the rules and standards that are understood by members of a group, and that guide and/or constrain social behaviour without the force of laws 5 ."Social norms are the public rules of action and thought, acting as the backbone of societal habits, routines, and customs, and legal frames. ${ }^{6}$ Social norms can be categorized into two: injunctive and descriptive social norms ${ }^{7}$. With the injunctive social norms, appropriate conduct is constituted by what others believe to be appropriate; in this sense, the norms will direct action by promising informal sanctions in the form of interpersonal approval or disapproval if that action is deemed relevant or not. With the descriptive social norms, appropriate conduct is constituted by one's perception of what most others do. The rationale underneath descriptive norms is that as many people are doing something, then it is probably a wise thing to do. There are, also, personal norms, which are non-social beliefs on attitudes, facts, and morals and property of individuals ${ }^{8}$ these are, fundamentally, perceived norms, which operate at the individual level. ${ }^{9}$

Much as the society in which the norm is lived is made up of people or institutions ranging from the most to the least influential ${ }^{10}$ will maintain the social norms through a systemic process of

\footnotetext{
5 Roberto Beno Cialdini , and Melanie R Trost, "Social Influence: Social Norms, Conformity and Compliance," The Handbook of Social Psychology, DT Gilbert, ST Fiske, and G Lindzey, eds., (New York, NY: McGraw-Hill), 152

${ }^{6}$ Piet Keizer, , "The Concept of Institution in Economics and Sociology: A Methodological Exposition," Tjalling C. Koopmans Research Institute Discussion Paper Series 07-25, (2007); James, Lincoln R, and Guillot, Didier, "Durkheim and Organizational Culture." 108-04. IRLE Working Paper 108104, (2004); John Searle, Making the Social World: The Structure of Human Civilization. (New York: Oxford University Press, 2010); Pina-Cabral, João de, "Afterword: What Is an Institution?," Social Anthropology 19, no. 4 (2011).

7 Robert Beno Cialdini,, "Descriptive Social Norms as Underappreciated Sources of Social Control," Psychometrika 72, no. 2 (2007): 264; McDonald, Rachel, and Christian, S Crandall. 2015. "Social Norms and Social Influence," Behavioral Sciences 3 (2015): 147.

${ }^{8}$ Lori Heise and Karima Manji, "Social Norms," (Birmingham, UK: University of Birmingham, 2016),2.

9 Rimal Rajiv N, and Maria K Lapinski. 2015. "A ReExplication of Social Norms, Ten Years Later." Communication Theory 25 (2015): 395- 409.
}

sanctioning (conjoint norms), it is the most influential in the society whose norms will count most (disjoint norms). ${ }^{11}$ These influential people will impress their norms on the less influential, and these less influential will begin using the norms in their sanctioning system.

In African settings, influence is organized mostly along with the gender, age, and religious structures. Patriarchy is still dominant in Africa, ${ }^{12}$ with the norms that are characterized by the "pattern of status inequality in which the higher status group (men) is perceived as more proactive and competent, and the lower status group (women) is seen as more reactive and emotionally expressive". ${ }^{13}$ Men and women, particularly the fathers and mothers, play the protective and moulding roles, respectively, of the sexual activities of the adolescents. The elderly are still respected in Africa because of the expected wisdom they have accumulated for having lived longer, ${ }^{14}$ being custodians of knowledge, decisionmakers, and mediators of dispute. ${ }^{15}$ The elderly in form of aunties and grandmothers are involved in the adolescents' sexual issues as mediators in the cases of conflicts in the adolescent sexual lives. With religion as involving beliefs, practices, and

${ }^{10}$ Mackie, Gerry, Francesca Moneti, Holly Shakya, and Elaine Denny, What Are Social Norms? How Are They Measured? (San Diego, New York: Center on Global Justice, UNICEF, 2015),39.

11 James Coleman,Foundations of Social Theory (Cambridge, MA: Belknap Press, 1994)

12 Hyden Goran, "Institutions, Power and Policy Outcomes in Africa," Power and Politics in Africa 2. (London: ODI, 2008),16); , Adrien Wing K. 2009. "Foreword," Muna Ndulo and Margaret Grieco, eds., Power, Gender and Social Change in Africa, (Newcastle: Cambridge Scholars Publishing, 2009),xiii)

${ }^{13}$ Cecilia L Ridgeway,., "Framed before We Know It: How Gender Shapes Social Relations." Gender and Society 23, no. 2, 2009:149.

14 Oluwabamide, Abiodun J., and Kokunre A. Eghafona, "Addressing the Challenges of Ageing in Africa" Anthropologist 14, no. 1, 2012: 62.

${ }^{15}$ Veronique Barbelet, , Fiona Samuels, and Georgia Plank, The Role and Vulnerabilities of Older People in Drought in East Africa. Progress, Challenges and Opportunities for a More Inclusive Humanitarian Response, (London: ODI, 2018), v. 
rituals related to the sacred, ${ }^{16}$ it constitutes an inextricable part of African society and it influences the socio-political and economic spheres. ${ }^{17}$ Religious people play the spiritual and advisory roles in the sexual activities of the adolescents.

\section{The Church and the 'No Sex Before Marriage' Social Norm}

The standing norm is "no sex before marriage." In the communities where the research was done, sex was traditionally linked to marriage. Young men and women were permitted to have sex when they were married either through a formal traditional wedding or after the elopement, which was interpreted as a non-formal way of marriage. However, after performing some rituals, it would be recognized as marriage. ${ }^{18}$ If a girl was caught having sex or she was discovered pregnant before marriage, severe punishments of either killing her or ostracising her were performed and could be facilitated directly by the close members of her family. Parents, in any case, were not supposed to show any sympathy. If the family did not exercise such punishments or showed sympathy, then the whole family would be stigmatized as shameful and would lose some social privileges like talking freely, giving advice to people, or participating in social functions.

Christianity cemented this norm of "no sex before marriage" and the sanctions with its doctrine of sex as a function meant for procreation within a marriage setting. Already in the early church, it was taught that sex is meant for procreation and not for enjoyment; by the 7th century, Pope Gregorius declared that a couple was impure if they gained any pleasure from sex. ${ }^{19}$ Among the moral norms on sexuality that played a major role in the Church for several centuries are, to mention but a few: sex

\footnotetext{
${ }^{16}$ Harold G. Koenig, 2009, "Research on Religion, Spirituality, and Mental Health: A Review" Canadian Journal of Psychiatry 54, no. 2, (2009): 284.

17 Agbiji, Obaji M and Ignatius Swart, "Religion and Social Transformation in Africa: A Critical and Appreciative Perspective," Scriptura 114, 2015:1\&5.

${ }^{18}$ An older person pointed out that there was another form of marriage whereby if a man met a girl he wanted to marry, he would either smear her with ghee or cow dung or place a small arrow in her father's house. Then, the father of the girl would be obliged to send her daughter to the man, or the girl was taken to the man's house.
}

before marriage as wrong; the main purpose of sex being procreation; sex as only acceptable within the confines of a marriage of one man and one woman, and; celibacy as a higher ideal than married life. ${ }^{20}$ The Church became an influential actor in the marriage institution, with the religious functionaries who are respected by almost everybody, performing the functions of teaching about marriage and blessing the marriage.

Breaking the norm is not without consequences resulting from the Church normative discourse of no sex before marriage. The pregnant adolescent is considered a prostitute who sleeps around with men: "Everybody sees you as a prostitute, as a sinner.", 1 For this matter, the adolescent might wish to run away and hide in a community that does not know her to avoid stigmatization. The "Church, communities and cultures use shame to protect the traditions of the culture and to keep religious laws sacred. Shame is directed at those who violate the rules". ${ }^{22}$ In order to cover up for this shame, for example, it was pointed out by the respondents that the Church in some places, categorized the son or daughter born out of sex before marriage as 'illegitimate,' and this, in the future, would deny them a chance of becoming religious functionaries; the parents of the pregnant adolescent would be denied religious services. The respondents added that, for example, they would be denied having Holy Communion, unless their child gets married in Church and/or participates in a social corporal punishment administered by the Church functionary.

Not always do social norms match with adolescent personal norms. It is for this matter that the social norm that there should not be sex before marriage is contested by adolescents who deliberately decide to get pregnant outside marriage for different

${ }^{19}$ Marilize E Tukker, 'Where sexuality and spirituality meet: An assessment of Christian teaching on sexuality and marriage in relation to the reality of $21^{\text {st }}$ century moral norms', HTS Teologiese Studies/ Theological Studies 69, no. 1, (2013):2

20 Peter Vardy, The puzzle of sex (London: HarperCollins, 1997), xi.

${ }^{21}$ Male Respondent 3, Village 1.

22 Tukker, 'Where sexuality and spirituality meet: An assessment of Christian teaching on sexuality and marriage in relation to the reality of $21^{\text {st }}$ century moral norms', p. 2 
reasons. ${ }^{23}$ For example, the respondent pointed out that they decide to get pregnant because they have not got a husband to marry them, but they have gotten someone to impregnate them; they engage in sex because they simply want sex for pleasure and nothing else linked to marriage or pregnancy; they engage in sex, as well, because they want a baby and not marriage; there are also cases whereby as a test before marriage, adolescents engage in sex for reasons of experiencing each other. In all these cases of sex before marriage, it is likely that the social norm shapes the context for action, for example, that the adolescents hide or do not speak about their relationships, but do not necessarily determine their action, as they will still go ahead with having sex and even get pregnant without caring or caring less about what the society thinks and says.

The tension between the personal beliefs that justify having sex and the social norm that prohibits the adolescents from having sex result in not only dangerous sex behaviours, but also dangerous acts in order to hide the sex activities, on the one hand, and the manipulative behaviours, on the other hand. The data shows that the adolescents hide in dangerous places, such as bushes in order to have sex; in the middle of sexually transmitted diseases, adolescent go in for unprotected sex; and with less education on sex, they go in for traumatic sex experiences, such as forced sex, commercial sex, etc. The adolescents pointed out that such traumatic experiences can disturb them later in their lives because some of them find out that they were used by men or even infected with sexually transmitted diseases and/or HIV and AIDS; with such experience, the adolescents end up hating men for

\footnotetext{
${ }^{23}$ Knowledge, beliefs and attitudes on social health, adolescent sexual behavior, attitude towards teen behavior, substance use, early menarche, materialism, risk perception, and individual levels of education can lead to early sex, and hence early pregnancies. See Carolyn Mbelwa, and Isangula Kahabi Ganka, Teen Pregnancy: Children Having Children in Tanzania (March 24, 2012) https://ssrn.com/abstract=20283 69 or http://dx.doi.org/10.2139/ssrn.2028369

${ }^{24}$ Woman Respondent 3, Village 1.

25 Petesch Patti, Bullock,Shelley Feldman et al, "Local Normative Climate Shaping Agency and Agricultural Livelihoods in Sub-Saharan Africa," Journal of Gender, Agriculture and Food Security 3, no. 1 (2018): 110-112.

${ }^{26}$ This concept of normative climate is not so common; it surfaced a couple of years back in the analysis of gender norms
}

the rest of their lives. Having fear for the social stigma that can result from having been discovered to have sex, adolescents end up carrying on abortions and committing suicide; sometimes, they hide pregnancies, and hence do not take care of them and end up getting complications. More still, parents and the adolescents end up in negotiations of manipulations in order to 'normativise' the apparently broken norm. The parents, for example, negotiate so that the pregnant adolescent can get married in Church as early as possible: "...It will be a matter of speeding up the process for marriage so that they are married before the stomach is huge, and she is fatigued". ${ }^{24}$ The reason as to why the process should be speedy is because it is not desirable that the society gets to know that the adolescent is pregnant. In this way, the adolescents and the society are in continuous state to overcome what is perceived as social constraints on the personal beliefs; and the society does not disturb them as such, hence the fluidity character of the norms of being less restrictive (normative relaxation) and dynamic (normative change). ${ }^{25}$

\section{Role of the Church: Transformation of the Sex Normative Climate from Shameful Sex to Responsible Sex}

The question at hand at this point is what the role of the Church is in the transformation of the 'no sex before marriage' social norm, which is based on the discourse of 'shameful sex', to 'sex outside marriage' social norm, which should be based on the discourse of 'responsible sex'. It is a question of sex normative climate change. ${ }^{26}$

as localized phenomena. The word 'climate' alludes to something prevailing like weather, but with changes, as well. The normative climate, thus, refers to the contextualized and prevailing social norms, which have the capacity to change because of the capacity to accommodate and integrate personal beliefs. For more details about local normative climate, see Petesch Patti and Shelley Feldman et al. "Community Typology Framed by Normative Climate for Agricultural Innovation, Empowerment, and Poverty Reduction" Journal of Gender, Agriculture and Food Security 3, no. 1 (2018); Petesch Patti and R Bullock et al. "Local Normative Climate Shaping Agency and Agricultural Livelihoods in Sub-Saharan Africa" Journal of Gender, Agriculture and Food Security 3, no. 1 (2018) 
As it has been described in this paper, the "no sex before marriage' social norm is enhanced through the Church teaching about sex for procreation, on the one hand, and marriage as an institution where sex can be experienced and as an inseparable union which is fundamentally sanctioned by God through the Church, on the other hand. ${ }^{27}$ Such teaching is based on insights of the early Church, with other elements, such as the sin of pleasure and hence sex for pleasure ${ }^{28}$ and celibacy as a higher ideal than married life. ${ }^{29}$ Sex in the Church is a subject of sexual shame. Such sex normative climate is unhealthy because it is built on a forced construct of necessity of the link between sex and marriage, on the one hand, and also a negative view about sex, on the other hand. Additionally, it is a consideration that conflicts fundamentally with the adolescents' discourse about sex and has led to not only dangerous sex behaviours and actions in order to hide sex activities, but also the manipulative behaviours.

The Church, in this sex quagmire, is called to be a facilitatory agent who will permit a development of the healthy sex social norm for the adolescents, a healthy local normative climate that moves away from the subject of sexual shame to responsible sex. Such a normative climate necessitates a shift of social norms orientation through creating new beliefs within the reference group in order that the collective expectations of the influential people allow new behaviours to emerge. The starting point is none other than the Book of the Song of Songs in the Bible. Much as the Book is mostly typically interpreted as the relationship between God and Israel or between Christ and the church, ${ }^{30}$ it is one of the greatest love poem ever written. ${ }^{31}$ Accordingly, a famous Rabbi Akiva declared: "The whole world is not worth the day on which the Song

27 Tukker, 'Where sexuality and spirituality meet: An assessment of Christian teaching on sexuality and marriage in relation to the reality of $21^{\text {st }}$ century moral norms'

${ }^{29}$ Vardy, Peter, The puzzle of sex (London: HarperCollins, 1997: xi).

30 Scheffler E. 'Eros as godsdiens (of die religieuse viering van seks)', HTS Teologiese Studies/Theological Studies 64, no 3 (2008), 1265 .

31 Du Toit D.R.S. "Liefkosings: Lekkerder as wyn liefdesgenieting in die boek Hooglied", in C. Vos \& H. Human of Songs was given to Israel; all the Writings are holy, but the Song of Songs is the holies of holies. ${ }^{32}$ The Book is one of the clearest biblical teaching on sexuality: a man and a woman are desperately in love with each other; they yearn to be together because they are in love, and the sex they enjoy with one another is an expression of that love.

It is a Book in which sexuality, sensuality, and marriage are praised..$^{33}$ The ultimate purpose of sex is to provide ultimate intimacy between lovers in a safe environment of love, trust, and commitment. The Book is a Song inviting to celebrate love: songs invite to join the song and dance; they invite to be joyful and get amazed at what people can do with the song. The Song gives importance to the role of senses of listening, seeing, tasting, smelling, and touching; there is no point in being negative with the physical desires and sexual feelings; in actual fact, the Book underlines that passion is beautiful and powerful. Last but not least, the Book underlines the issue that the love relationship encompasses all human experiences that involve the intellect and emotions in terms of longing, desire, admiring, wonder, enjoying, erotic, playfulness, and uniqueness of who is loved.

There is need for the Church to commit itself through its institutional settings to begin promoting sex education that gives advice and teaches about responsible sex. This is sex that is based on the values of sex that are biblically grounded: love, commitment, and consequence. There is no need for

(reds.), Liefde is die grootste (Pretoria: Protea Boekhuis, 2007), 121.

${ }^{32}$ Van Leeuwen R.C., "Song of Songs, Songs of Solomon", in C.W. Draper, C. Brand \& A. England (eds.), Holman Illustrated Bible dictionary (Nashville, TN: Holman Bible Publishers, 2003), 1518-1519.

${ }^{33} \mathrm{Du}$ Toit D.R.S., "Liefkosings: Lekkerder as wyn liefdesgenieting in die boek Hooglied", in C. Vos \& H. Human (reds.), Liefde is die grootste (Protea Boekhuis: Pretoria, 2007), 121-137. as interpreted by Tukker, Where sexuality and spirituality meet: An assessment of Christian teaching on sexuality and marriage in relation to the reality of $21^{\text {st }}$ century moral norms,' p. 2-3

67 | This work is licensed under a Creative Commons Attribution 4.0 International License. 
shaming the adolescents with sex, but to "teach them to value good communication in sex". ${ }^{34}$

\section{CONCLUSION}

The credibility of the Church by the young men and women is going to be measured and credited or not depending on the quality with which it will participate in the sex normative climate change in the formation or sustenance of sex social norms. The prophetic mission of the Church at this point is to facilitate the process of normativising a healthy sex normative climate through engagement in advice and teachings about responsible sex, which are biblical-based, rather than shameful sex. Time has come not to suffocate personal sex beliefs, but to incorporate and integrate them in a normative climate.

Through an analysis of the 'no sex before marriage' norm in Tanzania, the paper has shown how the Church is central in influencing the 'local normative climate.' The viability of any Church is going to be measured and credited or not, depending on the quality with which it will participate in the local normative climate change in the formation or sustenance of social norms, dealing with the social crises that stem from the breakage of social norms, actions/inactions against/for the oppressive sanctions, and in the negotiations. The paper calls the Church for action: to tirelessly, creatively and innovatively engage in social norms negotiation and normativisation processes of the existing social norms that are contested based on personal norms, on the one hand, and the personal norms that are contested based on the existing social norms, on the other.

\footnotetext{
${ }^{34}$ McClintock, K. A., Sexual shame: An urgent call to healing (Minneapolis, MN: Fortress Press, 2001),56-57.
}

68 This work is licensed under a Creative Commons Attribution 4.0 International License. 